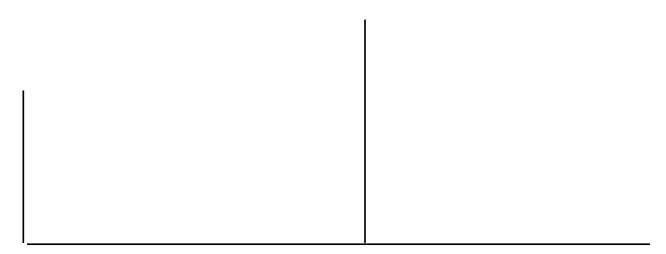

Rev. Latinoam. Psicopat. Fund., IX, 1, 32-43

\title{
Autoridade e responsabilidade parental do Estado no Brasil: história e ideologia
}

Gizlene Neder

\begin{abstract}
Neste trabalho enfocamos a história da idéia de autoridade presente nas instituições políticas periféricas do Estado na passagem à modernidade no Brasil. Interpretamos as ideologias que, sob os emblemas dos ideais monárquicos ou republicanos, a partir das opções entre dever e caridade, informam e dão suporte doutrinário às múltiplas tecnologias de controle social, com destaque para a documentação referida ao Asilo Nacional de Alienados.

Palavras-chave: Autoridade, assistência pública, controle social, ideologia
\end{abstract}


Neste trabalho ${ }^{1}$ enfocamos a história da idéia de autoridade presente nas instituições políticas periféricas do Estado na passagem à modernidade no Brasil. O período histórico enfocado engloba as últimas décadas do século $\mathrm{XIX}$ e as primeiras do $\mathrm{XX}$, quando ocorreram rupturas significativas devido ao fim do trabalho escravo (1888) e do regime monárquico (1889). Analisamos o processo de estruturação político-institucional do Estado, levando em conta as concepções sobre o desempenho da autoridade pública em relação aos alienados, presos, órfãos, velhos, mendigos e indigentes. Destacamos a situação dos asilos para alienados. Interpretamos as ideologias que, sob os emblemas dos ideais monárquicos ou republicanos, informam e dão suporte doutrinário às múltiplas tecnologias de controle social, empreendidas para assistir, reprimir, confinar, ou simplesmente abandonar a parte vulnerável da sociedade brasileira.

Trabalhamos o pensamento político de autoridades dirigentes de instituições, cujo poder decisório contingente movimenta o campo político. O estudo do pensamento destes ideólogos do terceiro/quarto escalão da estrutura administrativa do Estado brasileiro tem como objetivo identificar aspectos da cultura política nas formas de conceber, instituir e investir de autoridade os operadores sociais, designados na formação social brasileira como servidores públicos. Objetiva, também, descrever e interpretar a dinâmica, pendular e contraditória, do processo de sacralização e secularização do poder na sociedade brasileira, pontuada pelas opções entre a caridade e o dever. Para este artigo, fundamentaremos nossa análise na documentação do Asilo dos Alienados; chamado primeiramente Hospício D. Pedro II, posteriormente renomeado Hospício Nacional de Alienados.

Estamos levando em conta alguns aspectos históricos específicos. Em primeiro lugar, devemos considerar as permanências culturais, tendo em vista a herança do modelo institucional do Estado absolutista português, já tantas vezes referida pela historiografia brasileira (Buarque de Hollanda, 1976; Faoro, 1975), e sua inserção na cristandade ocidental latina. Em

1. Este trabalho insere-se em projeto integrado de pesquisa intitulado Assistência, abandono, repressão e função parental do Estado. Conta com o apoio da FAPERJ (Bolsas de IC e de Apoio Técnico) e do PIBIC/UFF-CNPq. Contamos com a participação de Gisálio Cerqueira Filho, Departamento de Ciência Política da UFF, nas discussões teóricas deste projeto integrado. 


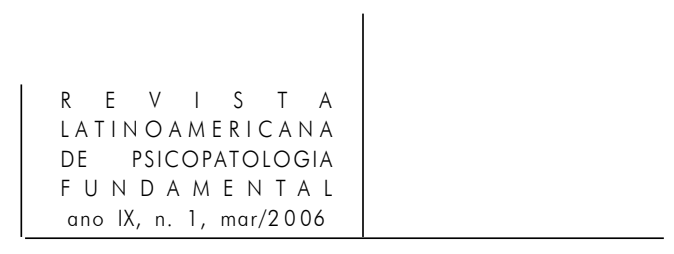

segundo lugar, devemos levar em conta a ruptura ensejada pela emancipação política (1822) e conseqüente processo de constituição do Estado.

Tanto num quanto noutro prisma (o da continuidade e o da ruptura), a produção historiográfica tem apresentado interpretações muito gerais relacionadas à grande obra política dos codificadores (a Constituição, o Código Criminal, o Comercial, etc.) ou à dinâmica político-partidária e as formas de governos (monarquia e república).

Para uma análise mais específica, focada na cultura política de autoridades públicas brasileiras, privilegiamos o período que vai desde fins do tráfico negreiro (1850) e da Guerra do Paraguai (1865) até a década de 1910, abarcando algumas décadas do Estado imperial e a reestruturação do Estado brasileiro sob a forma republicana. Este recorte cronológico tem como premissa dois aspectos históricos: estamos considerando o fim do tráfico como fator de estabilização demográfica dos trabalhadores escravos que, segundo pesquisas históricas mais recentes, implicou uma longevidade maior da população escrava (Reis, 1988). Os efeitos políticos desta longevidade apareceram em meados da década seguinte, com o aumento do protesto e da revolta escrava e com o aumento de velhos entre a população escrava que culminou na Lei dos Sexagenários (1884). As alforrias (de escravos velhos) estavam ocorrendo com freqüência; o aumento do abandono e do descaso por esta população também, que, alforriada e posta para fora da casa dos senhores, começou a engrossar as fileiras de mendigos e indigentes nas grandes cidades brasileiras. Data desta conjuntura, por exemplo, a criação dos asilos de mendicidade, vindo estes a se juntar, da parte do Estado, a um quadro variado de instituições assistenciais - todas religiosas, inclusive a Santa Casa de Misericórdia do Rio de Janeiro - devotadas à caridade. A Guerra do Paraguai, por sua vez, implicou seqüelas sociais que acentuaram as demandas ao Estado de suas responsabilidades parentais em termos de pensões às viúvas, aos inválidos e órfãos.

Como pode ser observado, estamos tentando fugir da datação mais usada pela bibliografia sobre este tema que se baseia na própria interpretação (autoreferente quanto aos seus pendores modernizadores) dos positivistas republicanos que tendem a ignorar os esforços instituintes do período monárquico. Ao mesmo tempo, não se deve fazer coro à tendência historiográfica monarquista (geralmente laudatória do império e da família real como moderna e piedosa quanto aos desvalidos). O enfoque da história política sob uma ótica institucional rígida (legislação, partidos etc.) tende a não privilegiar aspectos importantes da história social e da cultura política que estavam na base das demandas às responsabilidades parentais do Estado.

Por responsabilidade parental estamos entendendo, junto com Pierre Legendre (1983), o conjunto de práticas políticas e ideológicas encetadas a partir 


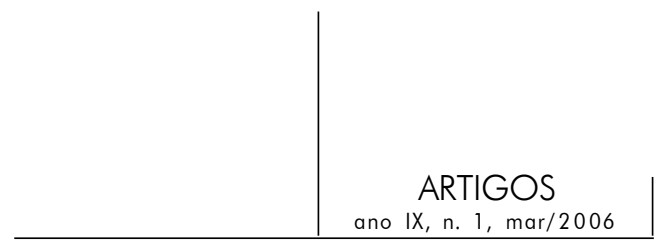

de um lugar de poder dentro de uma dada lógica institucional. A expressão aparece na obra de Legendre (1992) como fonction parentale, ou seja, função parental. Para o autor, a conceituação não é problematizada do ponto de vista da teoria sociológica funcionalista (pelo menos conscientemente), uma vez que ele trabalha muito mais sob influência do estruturalismo, e da psicanálise de corte lacaniana. Fazemos um pequeno deslocamento conceitual, afirmando a idéia de responsabilidade parental, exatamente porque apreendemos o significado do conceito usado por Legendre, que, na nossa leitura, está muito mais próximo da idéia de responsabilidade do que de função. Sobretudo, porque Legendre, trabalhando de forma multidisciplinar (com a História, o Direito e a Psicanálise), descortina em seus livros as marcas da cristandade latina na cultura política européia. Neste ponto, o autor busca na história da Idade Média aspectos constitutivos da identidade cultural européia (e, portanto, ocidental), para os quais a Igreja Romana e seus ritos, alegorias e ideologias são fundamentais.

Desse modo, podemos destacar que a origem da própria expressão latina spondere, que significa responder por, evoca o coro nas missas celebradas nos monastérios beneditinos, e que tinha por obrigação responder aos cânticos nas celebrações. O radical espos, que significa firmar um tratado, assumir um compromisso ou uma obrigação solene, “responder por alguém”, evoca, ainda, os esponsais, união de almas (entre esposos), numa clara alusão às implicações subjetivas e afetivas contingentes.

A responsabilidade parental do Estado não significa paternalismo, no sentido pejorativo; muito embora, em algumas situações históricas, a prática política e ideológica dos Estados venham revestidas de paternalismo no sentido estrito do termo. Geralmente, sob o paternalismo, verifica-se uma referência em excesso destas mesmas responsabilidades parentais e tende-se a produzir efeitos políticos, ideológicos e, sobretudo, sociais de fragilização dos segmentos mais vulneráveis da sociedade semelhantes àqueles onde ocorre a ausência da responsabilidade parental do Estado.

Para Legendre, o Estado constitui uma das possibilidades históricas, dentre as possíveis, de configuração do campo político e propicia a produção de efeitos jurídicos, sobretudo no caso da Europa (e seus prolongamentos ultramarinos) desde o segundo milênio. Portanto, os Estados (Status) nas sociedades modernas secularizadas têm implicações normativas e jurídicas fundamentais, mesmo na pós-modernidade (Legendre, 1992). Ainda que a lógica do mercado sob o liberalismo tenha levado, nas últimas décadas, às alusões radicais acerca do fim do Estado, ou do Estado-mínimo, sua dimensão cultural, do ponto de vista do campo político enquanto locus de produção e reprodução normativa instituinte do Interdito não deve dissolver-se, sob pena de vermos a própria cultura ocidental desmanchar-se... no ar. 


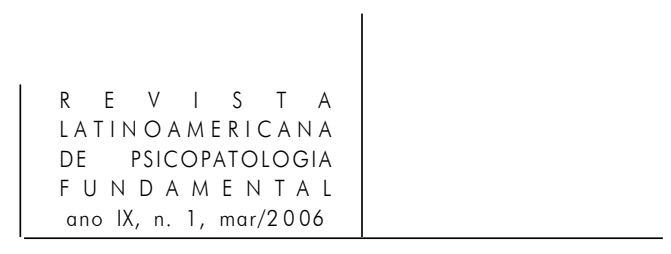

Como ocorreu, então, no interior do processo de estruturação do Estado, e do campo político no Brasil, o processo de filiação? E, dentro deste processo, como situar as diferentes concepções, percepções, emoções e procedimentos de sujeitos históricos investidos de autoridade, portanto, de responsabilidades parentais?

Além de relatórios oficiais, compulsamos uma rica fonte documental constituída por publicações, de caráter oficioso, ${ }^{2}$ contendo balanços ou relatórios de agentes históricos, atores políticos nestes postos do terceiro/quarto escalão da administração pública brasileira. Aproximadamente desde os anos 1870-80, alguns intelectuais, operadores sociais importantes na área da medicina, ${ }^{3}$ dentre outros setores, começam a produzir esta documentação, com a clara intenção de registrar, criticar, mostrando deficiências, ou tecer loas sobre seus próprios feitos.

Interessante observar que é na área da medicina que encontramos os primeiros balanços, visando o planejamento para as políticas do Estado. O pioneirismo dos médicos confirma uma das hipóteses de nossa pesquisa: a de que a responsabilidade parental do Estado, dirigida para assistir a parte vulnerável da sociedade, teria sido primeiramente projetada enquanto ação governamental pelos operadores da área médica. A assistência médica teria logrado um processo de secularização mais acentuado, pela ruptura empreendida pelo pensamento médicocientífico, que abraçou o positivismo. Os primeiros documentos são muito críticos e insistem nas carências, insuficiências e precariedades das instituições públicas.

Em termos da estrutura administrativa do Estado brasileiro, entre meados do século XIX até 1910-30, não encontramos grandes diferenças institucionais após a proclamação da República. Comparativamente, olhando para o processo histórico francês do período pós-revolucionário, sobretudo a partir da consolidação levada a cabo no período napoleônico, verificamos, lá, uma significativa mudança institucional. Tal não é o caso do Brasil. Encontramos para os anos de 1874 e 1889 e aqueles posteriores à proclamação da República, organogramas institucionais muito próximos para o Ministério da Justiça e dos Negócios Interiores, que geria todas estas políticas públicas que estamos observando. As alterações verificadas no segundo momento, o período que foi de 1890 a 1904, fase de implantação da estrutura administrativa republicana, foram muito pequenas.

2. Designamos oficioso, no sentido de que não se trata de um documento governamental oficial. Entretanto, a posição ocupada pelo autor na estrutura administrativa ou legislativa do Estado brasileiro torna seu texto avalista dos assuntos por ele tratados.

3. Ver, por exemplo, Brandão, J. C. Teixeira. Os alienados no Brasil; ver também, Moreira, Juliano. Notícia histórica sobre a evolução da assistência a alienados no Brasil (publicados originalmente em 1905). 


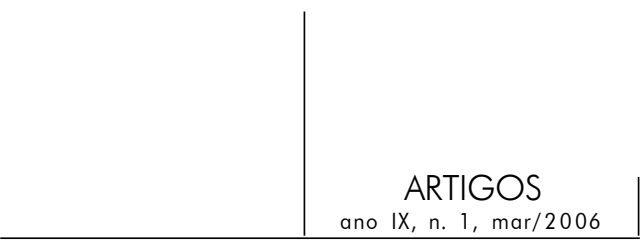

De sorte que não é exagero afirmarmos uma certa continuidade no que tange à administração das políticas públicas modernizantes que vinham sendo instituídas desde o segundo império, com os olhos postos no modelo institucional (e jurídicopolítico) napoleônico.

Os esforços instituintes podem ser observados a partir da década de 1850, quando encontramos preocupações com os limites e possibilidades do processo de institucionalização no Brasil. Assim, enquanto não foram estabelecidas instituições para abrigar meninos desvalidos, por exemplo, estes eram entregues aos párocos ou coadjutores, ou mesmo aos professores dos distritos. Neste particular, a intenção manifesta na criação de uma estrutura institucional moderna abriga práticas de salvaguardas que reeditam formas e estruturas vigentes desde o período colonial. Estas práticas remanescentes da governação colonial podem ser vistas através da manutenção dos elos com a estrutura institucional da Igreja (Pinto Venâncio, 1999).

A sociabilidade protocolar estabelecida entre os diretores de asilos, o ministro e as pessoas que davam donativos aos asilos era marcada por reverências e alusões à caridade, ao favor e à graça. Portanto, o modelo institucional no qual foram inspirados os asilos era o da Santa Casa de Misericórdia (Serrão, 1998). A imbricação entre Estado (cujos cofres do tesouro sustentavam as instituições asilares) e sociedade, por meio de ampla e conhecida rede de sociabilidade urbana, passava pelas irmandades religiosas leigas, que arrecadavam e distribuíam donativos, dentre outras iniciativas caritativas. Havia uma expectativa em relação à doação caritativa, propiciando, assim, uma rede de interferências e ruídos na formação de uma cultura política estatal autônoma e profissional.

Olhando bem de perto a estrutura das instituições asilares, podemos verificar muitos pontos em comum com as casas de correção, que empregavam o trabalho obrigatório dos jovens pobres, indigentes ou dos prisioneiros, na passagem à modernidade na Europa. Seja na Inglaterra elisabetana, com a Poor Law e o Vacrancy Act, ou no continente (Países Baixos ou França), uma distinção entre pobreza apta e não-apta para o trabalho começou a se firmar na cristandade européia atingida pelas reformas religiosas puritanas (protestante e católica) (Rusche e Kirchheimer, 1999). A pobreza considerada apta para o trabalho deveria ser punida, confinada em casas de correção ou numa instituição asilar: curar, educar, ou ressocializar criminosos, doentes mentais ou indigentes pelo e para o trabalho. ${ }^{4}$

4. A rica interpretação, vinda a lume em 1939, de Georg Rusche e Otto Kirchheimer, que trabalha a Criminologia e o Direito, na perspectiva da Escola de Frankfurt e que subsidia o Vigiar e punir, de Michel Foucault (1978), baseia-se em fonte documental significativa oriunda da demografia histórica francesa e alemã. 


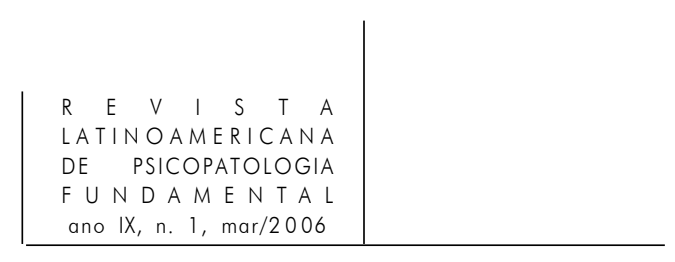

As políticas para assistir os segmentos vulneráveis da população no Brasil contavam sempre com a repressão. Neste sentido, não apenas a vadiagem era questão de polícia, mas a loucura, a pobreza, a indigência e a mendicância. Esta a razão de encontrarmos a invocação pendular e oscilante ora da assistência, ora da repressão. O pêndulo oscilava igualmente entre a invocação de políticas e práticas profissionais, científicas, modernas, republicanas, e a caridade, sempre a lembrar as permanências da antiga ordem.

A mesma interpretação que estamos fazendo para outras instituições assistenciais, na virada do século XIX para o XX, é válida para o Hospício Nacional de Alienados. Não identificamos uma ruptura digna de nota na passagem do regime monárquico para o republicano.

Havia um quadro de tensão ideológica entre a visão científica e profissional dos médicos e as forças políticas que vinham tradicionalmente conduzindo a assistência aos alienados, por meio de obras de caridade articuladas pela Santa Casa de Misericórdia. Sublinhe-se o fato de que, tanto em relação à assistência aos alienados quanto aos mendigos, instituições que ficavam circunscritas à administração municipal, havia uma preocupação com a origem domiciliar dos doentes e mendigos. Ao que tudo indica, como acontece na atual conjuntura, havia um deslocamento da população que necessitasse de atendimento e assistência para a capital, local que concentrava as políticas assistenciais. As autoridades da Capital, uníssonas, reclamavam da impossibilidade de atender adequadamente tanto desregramento. O ofício número 219 do diretor do Hospício Nacional de Alienados, doutor Pedro Dias Carneiro, de 22 de abril de 1902, confirma este fato. Segundo ele, um aviso de 15 de setembro de 1900, ancorado no decreto $\mathrm{n}^{\circ} 3244$ de 29 de março de 1899, informava que não cabia à administração municipal do Distrito Federal pagar as contribuições de enfermos indigentes naturais dos Estados, e caso aqui se encontrassem, deveriam provar que residiam neste município. ${ }^{5}$

Ao mesmo tempo, a condução da administração pela Santa Casa recebeu várias críticas do chamado "movimento alienista", que congregava médicos dedicados à medicina mental. Destaque deve ser dado às opiniões de João Carlos Teixeira Brandão, na liderança das críticas e do empenho pela implantação de uma medicina mental assistida, conforme os preceitos de cientificidade e modernidade exigidos na época. Orador contundente, debatedor irredutível e republicano ferrenho, Teixeira Brandão foi deputado e senador. Defendia o reconhecimento público da importância da assistência e do ensino da psiquiatria.

Teixeira Brandão participou, em 1883, de uma reunião da Sociedade MédicoPsicológica de Paris, onde comentou aspectos do Hospício Pedro II, ressaltando

5. Arquivo Nacional - Pacotilha IS 22 - (1902) Série Saúde, ofício n. 219. 


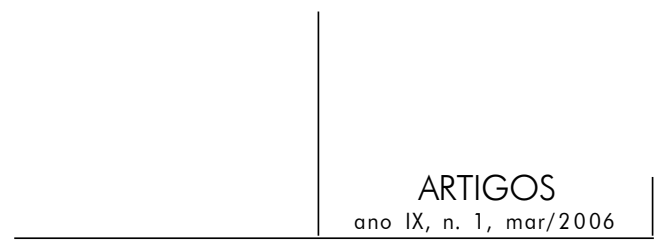

sua esplêndida localização geográfica e a beleza e imponência de sua arquitetura. Entretanto, no Brasil, sua militância ideológica e política não poupava críticas e denúncias, visando a reforma do hospício, através da medicalização do Pedro II. Seus opositores, por sua vez, criticavam sua filiação à escola francesa, apontando uma adesão mimética sem considerar as diversidades culturais e climáticas. A alusão a estas especificidades, sobretudo as de ordem geográfica, climáticas, era comum no contexto ideológico do paradigma científico na virada do século XIX para o XX, quando imperavam determinismos de toda sorte.

Porém, o verdadeiro ponto de discordância residia na dura crítica feita pelos médicos à administração do hospício pela Santa Casa de Misericórdia. Esta administração, colocada nas mãos de leigos e não de médicos, era feita a partir dos critérios de arrecadação de fundos caritativos e a direção era ocupada por administradores filtrados pela irmandade religiosa que administrava a Santa Casa. Encontramos, portanto, nesta disputa ideológica e política, o cerne da problemática que, no fundo, definia os campos da polarização. As críticas de Teixeira Brandão às irmãs de São Vicente de Paula eram muito freqüentes, destacando o poder que exerciam sobre o Hospício de Alienados, representando o poder clerical que interferia na instituição.

De fato, os médicos alienistas combatiam ideologicamente mais do que a força do segmento político representado pela Igreja no Brasil e suas obras caritativas. Combatiam, igualmente e ao mesmo tempo, no interior da administração do Estado brasileiro, no sentido de implantar uma assistência pública profissional (Luz, 1982).

Em 1903, ocorreu um episódio que açulou esta tensão entre médicos e Estado, e que resultou em uma guerra epistolar, onde pudemos observar mais de perto as falas sobre autoridade e responsabilidade parental do Estado. O episódio envolveu um marinheiro inglês que fora recolhido pela polícia no Hospício Nacional de Alienados, em 1901. Em 1903, o cônsul inglês no Rio de Janeiro solicitou informações sobre o doente. Estiveram implicados o médico doutor Marco Nery e o diretor A. Dias de Barros. A autoridade maior a que estavam submetidos era o ministro da justiça, J. J. Seabra.

Havia uma reclamação do diretor do asilo em relação ao médico que não respondeu à sua solicitação de informações sobre o estado de saúde do marinheiro. Abriu-se, assim, uma crise institucional, uma vez que o médico recusou-se a prestar as informações. ${ }^{6}$ A recusa do médico ocorria, como está informado no relatório, não só no caso do paciente inglês. Por fim, o diretor solicita orientação para que se pudesse tomar providências contra o médico, pois o regulamento da instituição não previra este tipo de problema. Num dos ofícios,

6. Arquivo Nacional - Pacotilha IS ${ }^{3}-23$ (1903) - Série Saúde, ofício n. 47. 


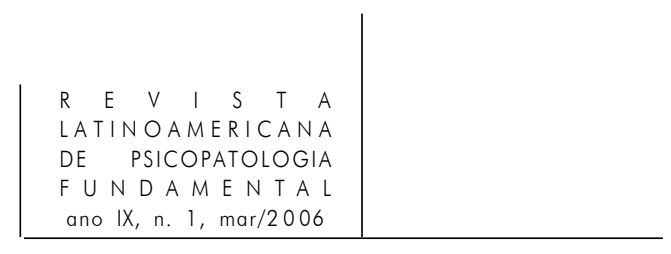

pudemos averiguar que havia uma picuinha entre o diretor e o médico e que, talvez, esta estivesse ocorrendo devido a algumas inovações administrativas que o diretor pretendia introduzir para “(...) tornar mais rápida, uniforme e impessoal o pedido de informações que houvesse de obter dos Snr ${ }^{\text {es }}$ clínicos instituir a praxe seguinte (...)". ${ }^{7}$

Segundo o diretor do asilo, o doutor Marco Nery de modo nenhum poderia deixar de prestar as informações exigidas, mesmo que entendesse que a praxe instituída para obtê-las não deviam mudar, cabendo-lhe tão-somente protestar junto a esta diretoria, ou junto ao ministro, mas nunca deixar de corresponder ao seu cumprimento. Informou ao ministro que a solicitação do consulado foi atendida e seguiu discutindo a crise de autoridade que se instalou, passando a averiguar e argüir o clínico. Sobretudo, o diretor solicitou informações sobre como proceder diante da desobediência do médico. Sem dúvida, neste conflito de autoridade, mesmo havendo um diretor nomeado, a condição social de médico, e o poder político conferido pelo diploma, tal como nas sociedades do Antigo Regime, conflitava com a autoridade republicana. Na verdade, o doutor Marco Nery comunicou que não se recusava a prestar as informações requeridas por qualquer familiar ou quem o representar, desde que fossem solicitadas de acordo com a praxe administrativa, e concluiu invocando procedimentos de corte; mencionou a praxe administrativa e o regulamento, e fez alusão à forma que ele considerou descortês da solicitação do diretor.

Aparentemente, médico e diretor seguiram sua rotina profissional. Encontramos outra referência ao doutor Marco Nery, desta vez para atestar as qualidades profissionais, seriedade e empenho de um aluno interno, estudante do $5^{\circ}$ ano da Faculdade de Medicina e Farmácia, Antônio Carlos Penafiel. Este atuou como auxiliar junto ao médico, e desejava tornar-se efetivo na vaga de internoauxiliar, que vinha ocupando interinamente. Todos os ofícios foram despachados pelo mesmo diretor do hospício, A. Dias de Barros. Interessante observar que, apesar do tratamento dado à correspondência protocolar entre as autoridades indicar uma sociabilidade republicana, com as saudações "saúde e fraternidade", os termos do ofício do requisitante da vaga efetiva de interno-auxiliar no hospício está carregado de referências e alusões à antiga ordem.

Moço pobre como sou, esperando encontrar nesta casa um auxilio que facilite a terminação do meu curso, tão penosamente feito até hoje, e, sendo ella um manancial fecundo para os estudos a que me dedico, especialmente os de ordem psychiatrica e nervos dos quaes sou religiosamente devoto, espero da generosidade e do espírito de justiça de $\mathrm{V} .{ }^{8}$

7. Arquivo Nacional - Pacotilha IS ${ }^{3}$ - 23 (1903) - Série Saúde, ofício n. 100.

8. Arquivo Nacional - Pacotilha IS ${ }^{3}-23$ (1903) - Série Saúde, ofício n. 74. 


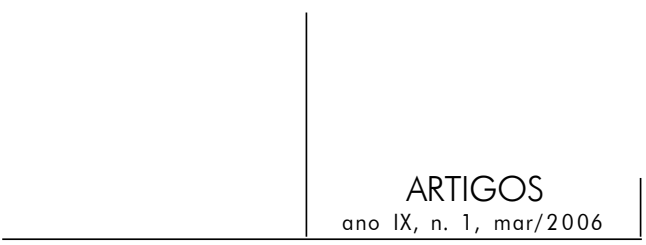

Mais que destacar as alusões à devoção, metaforicamente referidas como religiosa, que o estudante diz ter em relação à psiquiatria como indicação de uma permanência da velha ordem, devemos atentar para a demanda pela generosidade e espírito de justiça do ministro. Como exigir, então, nas relações institucionais entre as autoridades um comportamento profissional e técnico, como fez o diretor do hospício em relação ao médico rebelde, se as formas de recrutamento e acesso às carreiras estavam ainda marcadas pelas relações pessoais e paternalistas? E mais, como exigir que cumprissem suas responsabilidades parentais, enquanto representantes do Estado, se a visão de "espírito de justiça”, tal como concebida pelo interno-auxiliar, pobre (como afirmou), estava subordinada às qualidades pessoais e naturais do ministro, ocupante de um cargo público da mais alta hierarquia do governo republicano?

Bem sabemos que a naturalização da contingência deste "espírito de justiça” inscrevia-se num processo de simbolização que ligava a ocupação de um cargo tão importante à sua existência automática e obrigatória; fosse o ministro, pessoalmente, um indivíduo dotado ou não deste espírito. Não se tratava, portanto, de uma qualificação pessoal, mas natural, atribuída por critérios ligados à sua disposição da ordem natural das coisas e das pessoas, numa escala de múltiplas hierarquias. Tratava-se, portanto, da mais pura compreensão intelectiva do mundo católico, por meio das atualizações históricas do terceiro escolasticismo, que possibilitou o processo de apropriação cultural da filosofia tomista na virada do século XIX para o XX.

Portanto, insistimos no fato de que as políticas para assistir os segmentos vulneráveis da população, sem o profissionalismo almejado, acabavam contando com a repressão. Desse modo, identificamos a formulação de discursos políticoinstitucionais ambíguos e oscilantes entre a assistência e a repressão. Tal constatação, no entanto, não significa que não tenhamos encontrado (o que ocorreu com uma certa freqüência) casos onde a autoridade pública foi omissa, podendo sua prática política configurar uma situação onde o que observamos não foi nem a assistência, nem a repressão, mas o abandono. $\mathrm{O}$ abandono e a omissão podem ser vistos pelas ambigüidades decorrentes das indefinições entre o dever e a caridade.

Pensamos que vários dos problemas que vivenciamos hoje no campo das políticas públicas voltadas para educação e para o atendimento de famílias, crianças e adolescentes (prostituição infantil, abuso sexual, estupro, violência doméstica, abandono) não podem, por exemplo, ser solucionados sem que tenhamos clareza do processo histórico-cultural subjacente que molda a cultura política. A despeito de não deixarmos de considerar aspectos econômico-sociais relacionados à pobreza e à exclusão social (Prado Valadares, 1991), a cultura 


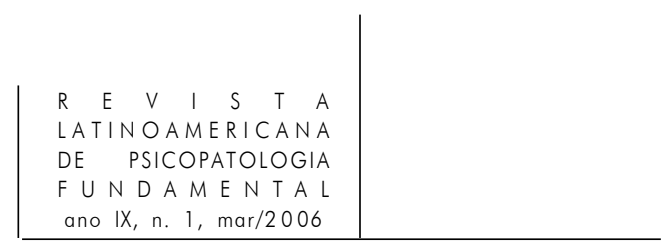

política constitui campo importante quando pensamos o encaminhamento de políticas governamentais.

Podemos afirmar, ainda, que os impasses das políticas públicas nestes mais de cem anos de ordem republicana (seja no campo assistencial, judicial, policial, ou educacional) se devem em boa parte à forma tímida como o Estado (paradoxalmente porque, no mais das vezes, forte e autoritário) não se incumbe de sua responsabilidade parental.

\section{Referências}

Brandão, J. C. Teixeira. Os alienados no Brasil. Arquivos Brasileiros de Neuropsiquiatria e Psiquiatria, Rio de Janeiro, ano II, n. 2, 1956.

Cerqueira Filho, Gisálio. Édipo e excesso: reflexões sobre Lei e Política. Porto Alegre: S. A. Fabris Editor, 2002.

Faoro, Raymundo. Os donos do poder. 2. ed. Porto Alegre/São Paulo: Globo/Edusp, 1975. $2 \mathrm{v}$.

Hollanda, Sérgio Buarque de. Raízes do Brasil. 9. ed. Rio de Janeiro: José Olympio, 1976.

LEGENDRE, Pierre. Les enfants du texte. Étude sur la fonction parentale des États. Paris: Fayard, 1992.

O amor do censor, ensaio sobre a ordem dogmática. Trad. do Colégio Freudiano do Rio de Janeiro: Aluísio Menezes e Potiguara Mendes da Silveira Jr. Rio de Janeiro: Forense-Universitária, 1983.

Luz, Madel. Medicina e ordem política brasileira - Políticas e Instituições de Saúde (1850-1930). Rio de Janeiro: Graal, 1982.

Moreira, Juliano. Notícia histórica sobre a evolução da assistência a alienados no Brasil. Rio de Janeiro: Arquivos Brasileiros de Neuropatia e Psiquiatria, 1955

Neder, Gizlene. Discurso jurídico e ordem burguesa no Brasil. Porto Alegre: S. A. Fabris Editor, 1995.

ReIs, João José (org.). Escravidão e invenção da liberdade. São Paulo: Brasiliense, 1988.

Rusche, Georg e Kirchheimer, Otto. Punição e estrutura social. Trad. Gizlene Neder. Rio de Janeiro: Freitas Bastos/ICC, 1999.

SERRÃo, José Veríssimo. A misericórdia de Lisboa, quinhentos anos de história. Lisboa: Livros Horizonte, 1998.

Valladares, Lícia do Prado. Cem anos pensando a pobreza (urbana) no Brasil. In: 


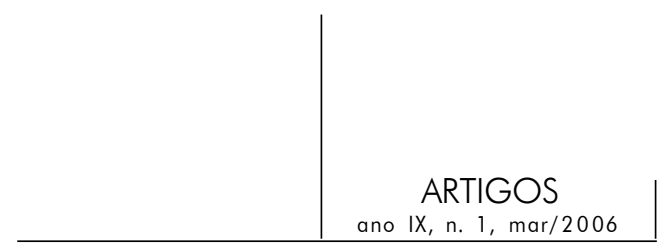

Boschi, Renato (org.). Corporativismo e desigualdade, a construção do espaço público no Brasil. Rio de Janeiro: Rio Fundo/IUPERJ, 1991. p. 81-112.

VenÂncio, Renato Pinto. Famílias abandonadas, assistência à criança de camadas populares no Rio de Janeiro e em Salvador - Séculos XVIII e XIX. Campinas: Papirus, 1999.

\section{Resumos}

En este trabajo discutimos la historia de la idea de autoridad, presente en las instituciones políticas periféricas del Estado en la pasaje a la modernidad en Brasil. Interpretamos las ideologías que, bajo ideales monárquicos o republicanos, a partir de opciones entre deber y caridad, informan e confieren soporte doctrinario a las múltiples tecnologías de control social, con destaque para la documentación del Asilo Nacional de Alienados.

Palabras claves: Autoridad, asistencia publica, control social, ideología

Dans ce travail on discute la histoire de la idée de autorité, dans les institutions périphériques de l'État, dans le passage a la modernité en Brésil. On analyse les idéologies, monarchistes ou républicaines qui, sous le devoir ou la charité, attribue pouvoir à les technologies de contrôle social. On détache la documentation historique de l'Asile National d'Alienés.

Mots clés: Autorité, assistance publique, contrôle social, idéologie

This article deals with the idea of authority in non-central political institutions of the State in the transition to modernity in Brazil. It analyses the ideologies that, under monarchial and republican ideals, through duty or charity, provided doctrinal support to the various technologies of social control. The documentation referring to the National Asylum for the Alienated (Asilo Nacional de Alienados) is given special importance.

Key words: Authority, public assistance, social control, ideology 